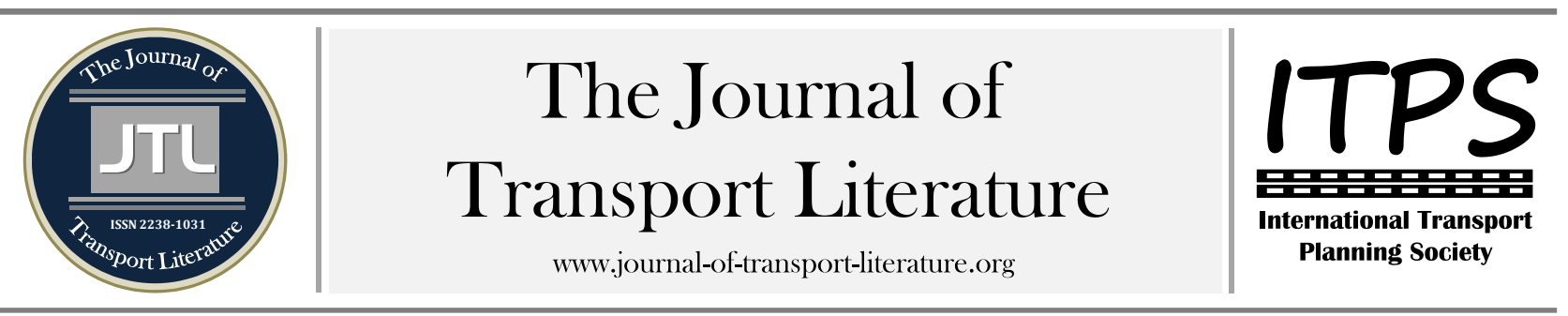

\title{
Changing the road transport for a rail transport to access a Brazilian airport
}

\author{
Anna Carolina Corrêa Pereira1,+; Leise Kelli de Oliveira²; Antônio Artur de Souza ${ }^{2}$ \\ ${ }^{1}$ Centro Federal de Educação Tecnológica de Minas Gerais, Belo Horizonte, Brasil \\ 2 Universidade Federal de Minas Gerais, Belo Horizonte, Brasil
}

\section{Article Info}

Keywords:

Airport

Private vehicles

Rail transport

Simulation

Stated preference

Submitted 27 Feb 2015;

received in revised form $26 \mathrm{Apr} 2015$

accepted 12 Jul 2015.

Licensed under

Creative Commons

CC-BY 3.0 BR.

\section{Abstract}

This paper reports a study aimed to assess whether passengers would change the road transport -whether individual transport (IT) or passenger bus transport (BT) -- for the rail transport to reach or leave the International Airport Tancredo Neves in Confins, State of Minas Gerais, Brazil. It also sought to identify the passengers' preference between the two transport modes. The study was built on two techniques: a questionnaire-based survey that approached 296 passengers, and a stated preference survey, which was answered by 223 of them. The results pointed out that most of the respondents were keen on changing the IT and BT for rail transport to reach and leave the airport. The rail transport had a good level of acceptance (84\%), which, was, however, contradicted by the stated preference results: $73 \%$ of the respondents stated they do prefer the individual transport. One of the possible reasons for the controversial results may be the way the data was collected and arranged in this study. The conclusion of the study was that the rail transport enjoyed good acceptance amongst the respondents when imagined in a static scenario.

+ Corresponding author. Centro Federal de Educação Tecnológica de Minas Gerais. Avenida Amazonas, 5253. 30421169 - Belo Horizonte, MG - Brasil.

E-mail address: annaccp@gmail.com.

\section{Introduction}

Because of its swiftness, air transports have become essential and increasingly popular for long distance journeys. Many airports, however, have been built on distant areas from the business center of the cities, causing a great volume of surface traffic to reach and leave the airport facilities. If the transport system is not efficient to meet this demand, it is likely to disturb not only the air traffic itself, but also those working or waiting at the airport and those living or working in the airport surroundings or along the roads leading to the airport.

Surface transportation from urban centers to airports may be impacted by a number of variables related to traffic and transportation systems, such as traffic jams, service availability and timetable of the public transport services. Increased use of public transport services (PT) and reduced use of individual transport (IT) have been pointed out as one of the means to overcome several issues related to passengers' journeys to and from the airports. Measures, however, are needed to make the public transport services appealing to most passengers. Gaining a better understanding of their profiles and preferences is crucial for planning and managing the transport modes. Although the government administrations, rather than the airline companies themselves, are in charge of providing access to and from the airports, several stakeholders, including airlines and store managers, have been concerned with the matter (BUDD, 2011).

In the International Airport Tancredo Neves (CFN), located approx. 25 miles from Belo Horizonte, the capital city of State of Minas Gerais, in Brazil, the main transport mode is based on the road system, whether relying on individual transports (IT) or the public bus transport (BT). As traffic jams on the way to and from the CFN airport have been constantly reported and ascribed to the excessive number of vehicles and the road infrastructure works that have been carried out in Belo Horizonte since 2012, debates have suggested that the implementation of a rail transport system would be an effective, if not the most or the only, solution in the region.

To add informed arguments to the debate, this study analyzes the passengers' preferences of transport mode to reach the CFN airport. Such an analysis is herein assumed to provide reliable information to contribute to the traffic planning in the metropolitan area of Belo Horizonte (Hutchinson, 1979). The contribution of understanding a population's preferences is twofold: at the micro-planning level, it may support improved services and better operational management; at the macroplanning level, it may support new strategies and guidelines aimed to improve and/or implement (new) public transport services according to the needs of the users.

This paper consists of six sections, including this Introduction. Sections 1 and 2 report reviews two studies that were used point of departure to the present investigation and a review of the literature on customer preference. Section 3 describes how data collection and analysis were carried out. Section 4 comprises the data analysis and discussion of findings. Section 5 contains final remarks. 


\section{Previous research on transport to an airport}

This section reports two studies carried out to identify the passengers' preference of transport modes - one in Sao Paulo, in Brazil, and the other in in Kota Baharu, a city in the Kelantan Province, in Malaysia. The techniques adopted in both studies were used as support to the present study carried out at the CFN airport, in Brazil.

Alves \& Strambi (2011) investigated the transport to the International Airport of Sao Paulo, in Brazil, focusing on systematic variations in the importance the passengers ascribed to factors impacting their choice for a transport mode to reach the airport, including journey time reliability. The journey time from São Paulo city center to the airport (approx. 15.5 miles) may vary from 40 minutes to over 2 hours on the road. The main reason for such a variation is the several different levels of traffic jams along the road depending of the day and time of the journey.

The aforementioned study was built on the analysis of face-to-face interviews carried out with 105 random passengers at the airport departure lounge in June 2005. The authors used the stated preference technique and conducted the interviews in three stages aiming at obtaining: 1) passengers' social and economic profile and data on their surface and air travels; 2 ) passengers' reaction to a proposal of express rail system and of a high-quality bus service driving direct to the airport; and 3) passengers' ordering of transport alternatives according to their preferences.

The authors carried out a fractional factorial experiment of three levels $(0,1$, and 2$)$ and three attributes (cost, expected journey time, and journey time reliability) (Souza, 1999). Building on these levels and attributes, they proposed 12 scenarios representing the different road and rail transport alternatives passengers would have to approach the airport considering journey time and time safety margin to reach the airport. The authors, then, asked the airport passengers to order their preferences in the different scenarios.

They collected data from 39 women and 66 men at age of 39 years in average. The passengers' major reasons for their travels were business (57\%) and leisure (34\%); the remaining 9\% were travelling either for both purposes or for reasons of other nature. The main range of individual income was over BRL 4.000/month (57\%); $20 \%$ of the passengers did not stated their income.

Only five passengers used more than two transport modes. The mode share was: private car (59\%), taxi (34\%), bus (5\%), and others (2\%). Taxi was more appealing for those travelling for business reasons than for those travelling for other purposes. The passengers' stated preference was strong toward a rail system: the train was chosen as the first option in $45 \%$ of the scenarios shown to the respondents; the car was the first option in $35 \%$ of the scenarios, but also had the lowest level of rejection, as it was the last option in only $16 \%$ of the scenarios.

Yazid et al (2012) investigated the relationship between travel distance and peoples' preference for either a motorized or a non-motorized transport mode in Kota Baharu. The authors used questionnaires to obtain the motorized passengers' opinion about their inclination to changing for a non-motorizing mode (e.g., on foot or by bicycle). Building on Ahern \& Tapley (2012) and Yazid et al (2012) contended that the questionnaires were the most indicated technique to collect the preference of actual and potential users when facing decision scenarios that prompt their immediate reaction.

The questionnaires comprised four parts, namely: 1) participants' general data; 2) journey data; 3) willingness to change from a motorized to a non-motorized transport; and 4) infrastructure and policies for non-motorized transport modes. The sample comprised 116 participants upon two months of data collection during Monday to Thursday workdays from July 25 through September 23, 2011.

The results showed that $67 \%$ of the participants used motorized vehicles as their main transport mode in the city. The most acceptable distances for the users to opt for walking on foot or riding a bicycle were, respectively, $8 \mathrm{~km}$ and $12 \mathrm{~km}$. The authors concluded that, in the near future, the sustainable structure for transportation in the city should be as follows: use of non-motorized modes for short-distance journeys, and use of public transport services (train and bus) for longdistance journeys. The authors, however, underscored that the use of sustainable transports requires governmental support and a reasonable policy strategy that targets public transport services of high level and infrastructure for bicycles and pedestrians.

\section{Customer preference}

Predicting the demand is an importance step in the process of planning the public transport system, and includes identifying the characteristics and the types of journeys common in a population. Three types of models have been reported to measure transport demand, namely (Hutchinson, 1979; Novaes, 1986):

Empirical, conventional models: They are focused on generation and distribution of journeys, modal share, and allocation of flows of vehicles to the transport network;

Behavior models: They are focused on the cause-and-effect relationships between the main attributes of the transport systems (e.g., perceived costs, waiting and journey time) and the passengers' possible decisions (Novaes, 1986);

Attitude models: They are focused on the most subjective factors underlying passengers' perception and psychological reasons, such as fear of being closed in small spaces or not being able to identify the station to alight (Novaes, 1986).

This study relies on the behavior models, which are related by Novaes (1986) to the consumer economics: a client may opt for one or several products building on the attributes of each of them and how they fulfill their needs. The attributes impacting on the user's decision are referred to as service variables. The set of values for such variables are referred to as service level (Novaes, 1986; Vasconcelos, 2005). The variables that are included in the service level for passenger transport are: time (total journey time, waiting time, reliability); cost (fare, fuel, toll, parking), safety (likelihood of accidents, state of walkways, roads, and traffic lights); comfort and convenience (distance on foot, Number of interchanges from a vehicle or transport mode to another, Number of intermediate stops (long-distance journeys, Physical comfort); environment quality (air conditioning and noise levels, compatibility between traffic type and local environment) (Novaes, 1986; Vasconcelos, 2005). In theory, such variables influence the users' decision for one or another transport mode. In practice, however, the users' may have different reactions and take a number of unpredictable decisions. The reason is that the user's attitude toward a number of different options is the result of personal interpretation, usually highly subjective and likely to be unpredictable (Novaes, 1986). 
The individuals' decision making concerning a good or a service go beyond rational factors and include such subjective factors as status, personal likes and dislikes, and desires. Novaes (1986) points out two presuppositions of the behavior models, namely:

[...] After listing, whether subjectively or objectively, a number of alternative options in the order of their preference, the individuals will always opt for the alternative that concomitantly suits their inclinations and is acceptable according to an analysis of their economical and social conditions, opportunity costs, and trade-offs.

The decision to use the public transport system involves a number of variables, including transport options, number of journeys, alternative destination places, means of transportation, part of the day, and day of the week.

The behavior models are built on a quantitative measurement of the users' preference. This measurement is based on the economic notion of utility and represented by a utility function (Novaes, 1986). The function is associated with a number of attributes of the product (in this case, the transport mode).

\section{Methodology}

Two techniques were used in this study to identify the passengers' preference concerning transport modes that are currently available in the metropolitan area of Belo Horizonte and one that has been proposed to link the city center to the CFN airport. The first technique, explained in Section 3.1, consisted of a survey based on closed-ended questions and asking participants to provide their preferences upon being showed images of three transport modes, namely: car, bus, and train. The second technique, explained in Section 3.2, consisted of obtaining stated preference data from the participants using flashcards with different scenarios representing possible journeys to the airport either by car or train.

In total, valid data from 296 passengers were collected using the first technique, and 223 of them accepted to participate further and contribute to the second part of the research, which was based on the second technique. The sample size for this second technique was estimated according to Souza's (1999) methodology. For this estimation, the software LMPC (Souza, 1999) was used and indicated a minimum sample of 102 participants. This explains why the difference of participants has no major impact on the results and comparability of the two techniques applied in this research. In addition, this also explains why this is a non-probabilistic sample, which yields results that cannot be generalized to the population (Zanella, 2006).

\subsection{Survey}

As aforementioned, a total of 296 passengers contributed to a survey carried out in the departure lounge of the CFN airport from August 2012 through December 2012. They filled out printed questionnaires containing mostly closed-ended questions, deemed as suitable for the research intent to collect information on their behaviors, attitudes, perceptions, demographic characteristics, and life style (Malhotra, 2006).

The questionnaires were used to collect the participants' profile and contained a question on a potential change of using the individual transport mode for using a public rail system, which is not yet available in the area. The aim was twofold: 1) to assess the likelihood of swapping modes, and 2) to collect the participants' reasons for not doing so at the moment and what should happen to change their minds.

The questionnaires were also used to ask the participants to order two currently available transport modes (bus and car) and a potential mode (rail transport) according to their preference. The passengers were supposed to carry out this task using three images which portrayed these three modes. The reason to use images was to make this a simple cognitive task for the participants. The available modes were supposed to be imagined as good quality modes, which were different from one another solely because of their inherent characteristics (e.g., individual or public, with or without integration with other transport modes). This task was considered a "direct" task of ordering because the participants could visualize the modes and order them according to their preference.

All data were inserted in an SPSS file. The analysis consisted of interpreting the frequency distribution of the participants' answers and ordering of the options. The stated preference, discussed in Section 3.2, however, was an "indirect" task, because it demanded more cognitive effort. The participants were provided flashcards with different scenarios and then asked to order them according to their preference.

\subsection{Stated Preference}

The stated preference technique was built on asking the participants to choose between hypothetical scenarios which were provided to them in flashcards. The research involved three attributes and two levels, resulting in eight scenarios. The attributes consisted of overall characteristics of a transport (i.e., journey time, access, and availability). The levels represented two transport/traffic conditions -- one usually associated with the private vehicle $(0)$; the other usually connected to the rail transport system (1). Specifically the levels were: with traffic jams or without traffic jams (for journey time), use of one transport mode or use of more than one transport modes (access), and reduced time rate or high time rate (of availability).

They were supposed to order the scenarios according to their preference in the light of a number of factors. This technique was used as a way to identify the participants' preferences in relation to scenario changes, such as increasing or reducing the variety of transport modes (e.g., implementing more bus lines and/or a new rail system). The ultimate aim was to estimate the highest likelihood of a given scenario being preferred at the expense of another (Brandli \& Heineck, 2005).

The ranking technique, the one used in this research, proposes ordering the options according to what the participants prefer the most to what they prefer the least (Novaes, 1986). The question was: "Considering these modes and scenarios, how do you order them from your top to your bottom preference?" The participants' responses were inserted in a ".oas" extension file and computed using software LPMC_1, v. 2.0 (Souza, 1999) before being analyzed using MS Excel spreadsheets.

\section{Results}

In general terms, the sample was balanced for sex and included mostly young adults (approximately $62.6 \%$ of the respondents were in the 18-39 year-old age group) with high level of education and employed in different sectors of the 
economy, specially in the private sector. The respondents' main reason for boarding an aircraft at the CFN airport was business (58.3\%), followed by leisure (29.3\%).

\subsection{Potential change of using private or public bus transport for using of a public rail system}

The respondents would consider swapping the current road transport mode (either IT or BT) for a rail transport mode $(84,1 \%) ; 7.32 \%$ stated they would "maybe" change or "it depends", $5.8 \%$ answered "no", and 2.78\% checked they "ignore of such a mode" or did not answered the question. The rail transport's rate of acceptance was, therefore, high, with the possibility of increase considering the potential to appeal to those $11.1 \%$ who answered "maybe" or "it depends", ignored of such a mode, or simply did not answer. The respondents stated that the most important criterion they would adopt before opting for a public rail transport service would be speed (21.5\%), followed by access (19.4\%), price (13.9\%), and safety $(12.8 \%)$. Other criteria were found in $32.4 \%$ of the answers. The respondents who stated they would "maybe" opt for a public rail service provided the following criteria to consider a potential change of system: availability, comfort, safety, and swiftness (37.5\%), access (28.1\%), disposable time, and journeys for private reasons $(6.3 \%)$. These respondents in general were not in favor of implementing the rail system: only $21.9 \%$ approved of the option.

The top reasons for not opting for a rail service included: dislike or distrust (43.5\%), preference for the private vehicle, specially when carrying bulky luggage $(52,1 \%)$, and need of flexibility to move from one place to another, specially among those who rent cars for business purposes (4.4\%). The businessmen alleged that a taxi would be too expensive and public services, as non-door-to-door alternatives, do not provide for their need to visit clients in different locations. Those who checked the option "Others" stated they would consider using the rail system if it were safe and easily accessed (33.3\%), if it were fast and practical (33.3\%), and if terminals, interchange stations and the system convenience had wide public exposure $(15.1 \%)$. The remaining respondents stated either that they would only consider using a rail service if they had no other option $(9.1 \%)$ or that they would never waive the comfort and convenience of a private car.

The rail transport had a good level of acceptance, as $84 \%$ of the respondents would consider this option provided that it met at least one of the following requirements: speed, access, price and/or safety (against theft). Interestingly, safety and access were the top criteria for both choosing a transport mode and swapping from the individual to the public transport. This finding suggests that these are criteria to which policy makers, city planners and rail project managers should pay special attention.

\subsection{Direct preference ordering}

The preference order of the 296 respondents of the questionnaire-based survey sample showed the top rates for first, second and third options followed suit: rail service (56.4\%), cars (35.8\%), and buses (58.4\%), respectively. The main reason underlying these results may be the very nature of the rail transport: when passengers get on the train or subway, they know for sure that they will not any face traffic jams as they would in the road system. In other words, the passengers may have related the rail transport to a first option which imposes no major obstacles to moving from one place to another provided that it meets some requirements, including reliability, safety, and comfort.

Some of the reasons for preferring the car as a second option may be flexibility and easy access, as it is a direct, door-todoor mode, with not undesired intermediate stops. The third position of the bus transport in the passengers' preference may be accounted for the lack of itinerary and timetable flexibility, need to walk to the bus stop, potentially long waiting time, need to watch for safety, and need to allot longer time to reach the airport.

\subsection{Indirect preference order (stated preference)}

The results of the stated preference were obtained building on a sample of 223 interviews. The coefficients obtained for the attributes "speed", "access" and "availability" were respectively 1.9977, -0.4606, and 0.9960. These numbers indicate the importance of the assessed attributes; the positive sign represents the utility of an attribute, and the negative sign represents the disutility of an attribute. Therefore, "speed" was considered a utility by the participants, that is, its positive sign indicates that the transport service should be fast. The other two attributes, "availability" and "access" had negative signs and, therefore, constituted a disutility function.

The results were significant at an acceptable level of Rho $=0.3070$ (Ortúzar; Willumsen, 1990). The t test indicated that the results were statistically significant because they were higher than 1.96 (95\% confidence) for all variables: speed (15.3475), access (-4.3588), and availability (-9.2077). The coefficient analysis indicated that speed (58\%) was the greatest valued attribute, followed by availability (29\%) and access (13\%). The utility of each scenario was computed using Equation 1 below.

$$
\text { Uexperiment }=1.9977 \mathrm{X} 1+(-0.4606 \mathrm{X} 2)+(-0.9950 \mathrm{X} 3)
$$

where X1 stands for speed, X2 for access, and X3 for availability.

The utilities shed light on the probability of occurrence of each scenario. The results indicate that the users prefer the individual transport to reach the airport (39.4\%), even under negative conditions, such as traffic jams and/or reduced time rate of availability. Only $27 \%$ of the respondents were likely to use the rail system in scenarios with negative circumstances for individual transport, such as traffic jams, and/or in scenarios with negative circumstances for the public system, such as reduced time rate of availability.

The results indicated that the respondents prefer to travel using one single mode by vehicles that are available at any time moving on roads with no traffic jam. In a way, the present results seem to represent the actual scenario of the airport in 2012, except for traffic jams in some parts of the day. In other words, the results are quite similar for the passengers' actual transport mode used to reach the CFN airport and for their stated preference: $74 \%$ of them used a private vehicle, and $26 \%$ used more than one transport mode.

The descriptive statistics also pointed to an intriguing result for the preference for a given transport mode at the expense of another: including a rail service changed the passengers' preference to this mode in the first place, followed by the car and the public bus service. The stated preference results, in contrast, showed that the passengers' preference for a rail system would be in the second place, following the car option. This result runs counter those reported in Ahern and Tapley (2012) and Scherer and Dziekan (2013). The respondents of the present research were also inclined to using more than a transport mode in circumstances of normal traffic, irrespective of the time rate of service availability. The most undervalued 
scenarios were those with intense traffic, which seems to be indicative of the passengers' fear caused by the constant traffic jams in Belo Horizonte and its metropolitan area.

The most relevant of the attributes herein analyzed was the speed to move from one place to another, followed by access to the transport system and the time rate of service availability -- the first one defined as a utility, and the remaining as a disutility. The time frequency of service was regarded an inutility, indicating that this is a factor that may influence the passengers' decisions and make them opting for bus services in a reduced number of circumstances.

\section{Conclusion}

This paper reports a study aimed to assess whether passengers would change the road transport -- whether individual transport (IT) or passenger bus transport (BT) -- for the rail transport to reach or leave the International Airport Tancredo Neves in Confins, State of Minas Gerais, Brazil. The results pointed out that most of the respondents were keen on changing the IT and BT for rail transport to reach and leave the CFN airport. The rail transport had a good level of acceptance, as $84 \%$ of the respondents would consider this option provided that it met some requirements, including: high speed, easy access, inexpensive price, and high safety (against thefts). The reasons for not using the rail transport included: luggage, need of flexible travels, non-acceptance, and distrust. This result was reassured when the respondents were asked to order their preferences of transport mode: the rail transport was their first option of choice to reach the airport, followed by the private vehicle and the bus.

However, the stated preference results point to another direction: $73 \%$ of the respondents stated they prefer the individual transport. One of the possible reasons for these divergent results may be the way of collecting and arranging the data. When asked, in the direct task, to order images of the transport modes (bus, private vehicle, and train), the respondents had the cognitive task of quickly imagining the characteristics of each of the transport modes before putting them in order of preference. By doing so, they might have been influenced by the image of the rail transport as traffic jamfree and faster than the other transport modes. They might also have neglected the need of using other transport modes before reaching the rail transport station.

On the other hand, for the stated preference, the passengers should arrange not only the transport modes, but also potential scenarios, including traffic jam and reduced time rate of availability. As these scenarios are more dynamic, the cognitive task was that of imagining and visualizing each potential circumstances. By doing so, the respondents may have imagined the need of changing trains, and therefore, may have opted for a more flexible and swift mode, such as the individual transport. This might explain the reduced preference for the trains in this study. Yet, this hypothesis should be further investigated.

The conclusion of the study was that the rail transport enjoyed good acceptance between the respondents when imagined in a static scenario, in this sense confirming studies such as the authors in Ahern and Tapley (2012) and Scherer and Dziekan (2013). Nevertheless, in the simulation of an actual scenario with a rail transport service, the respondents preferred the private vehicle, while the rail transport ranked as their second option. Albeit the results are exploratory, a number of variables seem to show that implanting a rail transport system to reach the CNF airport may be an important factor to improve mobility and sustainable development of the city of Belo Horizonte.

\section{Acknowledgements}

The authors wish to acknowledge CAPES (Coordenação de Aperfeiçoamento de Pessoal de Ensino Superior) for funding the first author's master degree.

\section{References}

Ahern, A., \& Tapley, N. (2012) The use of stated preference techniques to model modal choices on interurban trips in Ireland. Transportation Research Part A. Doi: 10.1016/j.tra.2007.06.005 (2007) apud Yazid, M. R. M.; Ismail, R.; Rahmat, R. A. O. K.; Nazri, M. City residence prepares towards implementation local lane of non motorized. Research Journal of Applied Sciences, Engineering and Technology, Selangor, v. 4, n. 5, p. 481-485.

Alves, B. B., \& Strambi, O. (2011). Escolha de modo no acesso terrestre a aeroportos considerando a confiabilidade do tempo de viagem. Transportes, v. 19, n. 1, p. 59-67.

Brandli, L. L., \& Heineck, L. F. M. (2005). As Abordagens dos Modelos de Preferência Declarada e Revelada no Processo de Escolha Habitacional. Ambiente Construído, Porto Alegre, v. 5, n. 2, p. 61-75, abr./jun.

Budd, T., Ison, S., \& Ryley T. (2011) Airport surface access in the UK: A management perspective. Research in Transportation Business \& Management, v. 1, p. 109-117.

Hutchinson, B. G. (1979). Princípios de planejamento dos sistemas de transporte urbano. Trad. Henrique Oswaldo Monteiro de Barros. Rio de Janeiro: Ed. Guanabara Dois, Rio de Janeiro. 416p.

Malhotra, N. K. (2006). Pesquisa em marketing: uma orientação aplicada. 4. ed. Porto Alegre: Bookman.

Novaes, A. G. (1986). Sistemas de Transportes. Volume 1: análise da demanda. São Paulo: Editora Edgard Blucher

Ortúzar, J. D.; Willumsen, L. “Modelling transport”. United Kingdom. Ed. John Wiley \& Sons, 1990.

Redman, L., Friman, M, Gärling, T., \& Hartig, T. (2013). Quality attributes of public transport that attract car users: a research review. Transport Policy, v. 25, p. 119-127.

Scherer, M., \&Dziekan, K.(2012). Bus or rail: an approach to explain the psychological rail factor. Journal of Public Transportation, v. 15, n. 1.

Souza, O. A. (1999). Delineamento experimental em ensaios fatoriais utilizando a técnica de preferência declarada. Tese de doutorado. Universidade Federal de Santa Catarina, Departamento de Engenharia de Produção.

Vasconcellos, E. A. (2005). A cidade, o transporte e o trânsito. São Paulo: Prolivros.

Yazid, M. R. M., Ismail, R., Rahmat, R. A. O. K., \& Nazri, M. (2012). City residence prepares towards implementation local lane of non motorized. Research Journal of Applied Sciences, Engineering and Technology, Selangor, Malaysia, v. 4, n. 5, p. 481-485.

Zanella, L. C. H. (2006) Metodologia da Pesquisa. Florianópolis: SeaD/UFSC, 144 p. 